\title{
Synthesis of the Unsaturated Anions $\left[\mathrm{MMoCp}\left(\mu-\mathrm{PR}_{2}\right)(\mathrm{CO})_{5}\right]^{-}(\mathrm{M}=$ Mn, $R=$ Ph; $M=R e, R=C y)$ : Versatile Precursors of New Heterometallic Complexes
}

\author{
M. Angeles Alvarez, ${ }^{[a]}$ M. Esther García, ${ }^{[a]}$ Daniel García-Vivó, ${ }^{*[a]}$ Estefanía Huergo, ${ }^{[a]}$ Miguel A. Ruiz ${ }^{[a]}$
}

\begin{abstract}
An efficient synthetic route for the preparation of the title anions has been set forth, involving two-electron reduction with $\mathrm{Na}(\mathrm{Hg})$ of the iodide-bridged complexes $\left[\mathrm{MMoCp}(\mu-\mathrm{I})\left(\mu-\mathrm{PR}_{2}\right)(\mathrm{CO})_{5}\right]$. Reaction of these anions with $\left(\mathrm{NH}_{4}\right) \mathrm{PF}_{6}$ (in THF) and $\mathrm{ClSnPh}_{3}$ (in $\mathrm{MeCN})$ gave $\left[\mathrm{MMoCp}(\mu-\mathrm{H})\left(\mu-\mathrm{PR}_{2}\right)(\mathrm{CO})_{5}\left(\mathrm{NH}_{3}\right)\right]$ and $[\mathrm{MoReCp}(\mu-$ $\left.\left.\mathrm{PCy}_{2}\right)\left(\mathrm{SnPh}_{3}\right)(\mathrm{CO})_{5}(\mathrm{NCMe})\right]$, respectively, with incorporation of the corresponding electrophile at either a bridging $\left(\mathrm{H}^{+}\right)$or terminal $\left(\mathrm{SnPh}_{3}\right)$ position, and addition of an external ligand $\left(\mathrm{NH}_{3}\right.$ or $\mathrm{NCMe}$, respectively), to render electron-precise derivatives ( $d_{\mathrm{Mo}-\mathrm{Re}}>3.1 \AA$ ) . In contrast, reaction with $\left[\mathrm{AuCl}\left\{\mathrm{P}(p \mathrm{Tol})_{3}\right\}\right]$ yielded stable unsaturated trimetallic clusters $\left[\mathrm{AuMMoCp}\left(\mu-\mathrm{PR}_{2}\right)(\mathrm{CO})_{5}\left\{\mathrm{P}(p \mathrm{Tol})_{3}\right\}\right]\left(d_{\mathrm{Mo}-\mathrm{Mn}}=2.71\right.$ A).
\end{abstract}

\section{Introduction}

The chemistry of polynuclear transition metal compounds featuring metal-metal multiple bonds have been an active area of research over the years, stemmed by the increased reactivity of these compounds toward an immense variety of organic and inorganic molecules, when compared to related mononuclear complexes. ${ }^{[1]}$ In addition, the description of the $\mathrm{M}-\mathrm{M}$ interactions in these systems remains as an active and challenging topic of current interest. ${ }^{[2]}$ Most of the multiply-bonded complexes studied so far are built from two identical transition metal centers while those having different metals (heterometallic complexes) have been historically less studied, ${ }^{[3]}$ in spite of the potential benefits in terms of reactivity and catalytic activity which might arise from the intrinsic polarity of the heterometallic $\mathrm{M}-\mathrm{M}$ ' bonds and differences in the respective coordination environments. ${ }^{[3-4]}$ The comparatively limited number of studies on heterometallic systems can be explained by either the lack of efficient synthetic methods to prepare these complexes, or their ready degradation to mononuclear compounds in the course of their reactions. Therefore, the preparation of new complexes featuring heterometallic $\mathrm{M}-\mathrm{M}$ ' multiple bonds and stabilized toward degradation remains an attractive target in this area.

Previously we have carried out a systematic study of the synthesis and reactivity of highly unsaturated binuclear complexes stabilized by P-donor bridging ligands. ${ }^{[5]}$ Of particular relevance was the synthesis of the 30 -electron anions $\left[\mathrm{M}_{2} \mathrm{Cp}_{2}(\mu\right.$ $\left.\left.\mathrm{PCy}_{2}\right)(\mu-\mathrm{CO})_{2}\right]^{-}\left(\mathrm{M}=\mathrm{Mo}^{[6]} \mathrm{W}^{[7]}\right)$, prepared via two-electron reduction of the corresponding halide-bridged complexes

[a] Departamento de Química Orgánica e Inorgánica/IUQOEM, Universidad de Oviedo, E-33071 Oviedo, Spain.

E-mail: garciavdaniel@uniovi.es

http://www.unioviedo.es/grupomaruiz/

Supporting information and ORCID(s) from the author(s) for this article are available on the WWW under the link.
$\left[\mathrm{M}_{2} \mathrm{Cp}_{2}(\mu-\mathrm{X})\left(\mu-\mathrm{PCy}_{2}\right)(\mathrm{CO})_{2}\right](\mathrm{M}=\mathrm{Mo}, \mathrm{X}=\mathrm{Cl} ; \mathrm{M}=\mathrm{W}, \mathrm{X}=\mathrm{I})$. $^{[6-7]}$ These anions turned to be a key entry point to the chemistry of a great variety of unsaturated complexes having hydride, alkyl or alkoxycarbyne functionalities, which also display a remarkable chemical behavior. ${ }^{[5]}$ It was therefore of interest to extend these studies to the preparation of related heterometallic unsaturated anions, so as to analyze the influence that the presence of two different metals would have on the reactivity of these unsaturated species. In this communication we report the synthesis of the 32-electron anions $\left[\mathrm{MMoCp}\left(\mu-\mathrm{PR}_{2}\right)(\mathrm{CO})_{5}\right]^{-}(\mathrm{M}=$ $\mathrm{Mn}, \mathrm{R}=\mathrm{Ph}(\mathbf{2 a}) ; \mathrm{M}=\mathrm{Re}, \mathrm{R}=\mathrm{Cy}(\mathbf{2} \mathbf{b})$ ) which, to the best of our knowledge, are the first examples of organometallic anions with group 6-7 metals having multiple $\mathrm{M}-\mathrm{M}$ ' bonds. ${ }^{[8]}$ A preliminary study of their reactivity toward simple electrophiles yielded several new compounds having $\mathrm{Mo}-\mathrm{M}$ and $\mathrm{Mo}=\mathrm{M}$ bonds, thus proving their utility as precursors of new heterometallic complexes.

\section{Results and Discussion}

The synthesis of the title anions was accomplished in two steps starting from the readily available precursors $[\mathrm{MMoCp}(\mu-\mathrm{H})(\mu-$ $\left.\left.\mathrm{PR}_{2}\right)(\mathrm{CO})_{6}\right]\left(\mathrm{M}=\mathrm{Mn}, \mathrm{R}=\mathrm{Ph} ;{ }^{[9]} \mathrm{M}=\mathrm{Re}, \mathrm{R}=\mathrm{Cy} \mathrm{y}^{[10]}\right)$, and involving in both cases a reduction of the isolable iodide complexes $\left[\mathrm{MMoCp}(\mu-\mathrm{I})\left(\mu-\mathrm{PR}_{2}\right)(\mathrm{CO})_{5}\right](\mathrm{M}=\mathrm{Mn}, \mathrm{R}=\mathrm{Ph}(\mathbf{1 a}) ; \mathrm{M}=\mathrm{Re}, \mathrm{R}=$ Cy (1b)) (Scheme 1). We note that the Mn complex 1a had been previously reported by Mays and col., ${ }^{[11]}$ and we have now prepared the $\mathrm{Re}$ analogue $\mathbf{1 b}$ in high yield by following a similar procedure. In a first stage, deprotonation of the abovementioned Mo-Re hydride with DBU (1,8-Diazabicyclo[5.4.0]undec-7-ene) followed by reaction with $\mathrm{I}_{2}$ leads to the formation of a mixture of the hexacarbonyl iodide complexes $\left[\mathrm{MoReCp}(\mu-\mathrm{I})\left(\mu-\mathrm{PCy}_{2}\right)(\mathrm{CO})_{6}\right]$ and $\left[\mathrm{MoReCpl}\left(\mu-\mathrm{PCy}_{2}\right)(\mathrm{CO})_{6}\right]$ in ca. 1:1 ratio. Although the related reaction for the $\mathrm{Mn}$ substrate led exclusively to the I-bridged isomer, the formation of two isomers for the Re system was not fully unexpected, if we recall that reaction of the related anion $\left[\mathrm{MoReCp}\left(\mu-\mathrm{PPh}_{2}\right)(\mathrm{CO})_{6}\right]^{-}$with $\mathrm{I}_{2}$ gave a similar mixture of isomers. ${ }^{[12]}$ In a second stage, the above mixture is decarbonylated by irradiation with visible-UV light to give the pentacarbonyl iodide-bridged derivative $\mathbf{1 b}$ as the only product. Spectroscopic data for this compound (see the $\mathrm{SI}$ ) are comparable to those of the Mn complex $1 \mathrm{a}$, revealing the structural similarity between these compounds. In particular, its IR spectrum displays five $\mathrm{C}-\mathrm{O}$ stretching bands, with the three more energetic ones being indicative of the presence of a fac$\operatorname{Re}(\mathrm{CO})_{3}$ oscillator in a low symmetry environment (2020 (vs), $1991(\mathrm{w}), 1923$ (sh, m) cm $\left.{ }^{-1}\right) \cdot{ }^{[13]}$ 


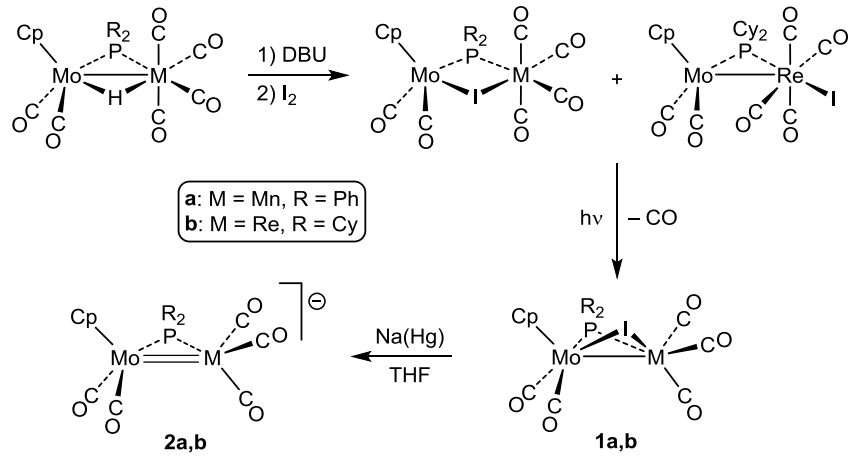

Scheme 1. Synthesis of Unsaturated Anions 2.

The iodide complexes $\mathbf{1 a , b}$ are finally reduced with $\mathrm{Na}(\mathrm{Hg})$ in THF to give strongly colored solutions (2a) or suspensions (2b) of the $\mathrm{Na}^{+}$salts of corresponding unsaturated (32-electron) anions, in an essentially clean manner ready for further use (see the SI). Unfortunately, all our attempts to obtain crystals or isolate salts of these anions have been hampered so far due to their rapid decomposition upon manipulation.

Anions 2 display in each case four $\mathrm{C}-\mathrm{O}$ stretching bands at ca. $1970(\mathrm{~s}), 1880(\mathrm{~s}), 1860(\mathrm{~s})$ and 1805 (w) $\mathrm{cm}^{-1}$, indicative of the presence of a pyramidal $\mathrm{M}(\mathrm{CO})_{3}$ oscillator in these molecules. ${ }^{[13]}$ This is clearly indicated by the symmetric (more energetic) stretch of these complexes, which displays a remarkable increase in intensity and is displaced some $30 \mathrm{~cm}^{-1}$ below the corresponding stretch of the saturated anions $\left[\mathrm{MMoCp}\left(\mu-\mathrm{PR}_{2}\right)(\mathrm{CO})_{6}\right]^{-}{ }^{[11-12]}$ as expected. To obtain additional information on the structure and bonding for these highly reactive species we then resorted to DFT-calculations. ${ }^{[14]}$ The gas-phase B3LYP-optimized structure of anions 2 (Figure 1 and $\mathrm{SI})$ is built from $\mathrm{M}(\mathrm{CO})_{3}$ and $\mathrm{MoCp}(\mathrm{CO})_{2}$ fragments bridged by phosphanyl ligands in asymmetric coordination $(\Delta d$ ca. $0.2(2 \mathrm{a})$ and 0.1 (2b) $\AA$ ). The DFT-computed C-O stretches for these species almost perfectly match the ones recorded in solution (see Table S6), after taking into account the typical 5-10\% overestimation of DFT-computed IR frequencies, ${ }^{[15]}$ and then exclude the presence of tight ion-pairs or solvated species in solution. Interestingly, the intermetallic separations of 2.726 (2a) and $2.859 \AA \mathbf{~} \mathbf{2} \mathbf{b})$ are nearly $0.3 \AA$ shorter than those measured for the singly bonded complexes $\left[\mathrm{MoMnCp}(\mu-\mathrm{H})\left(\mu-\mathrm{PPh}_{2}\right)(\mathrm{CO})_{6}\right.$ ] $(3.088(1) \AA)^{[9]}$ or $\left[\mathrm{MoReCpl}\left(\mu-\mathrm{PPh}_{2}\right)(\mathrm{CO})_{6}\right](3.136(1) \AA),{ }^{[12]}$ or the ones computed at the same level for the corresponding electronprecise (34-electron) anions [3.05 (Mn) and $3.16 \AA(R e)]$, therefore supporting the formulation of Mo-M double bonds. This view also agrees with other bond indicators calculated for the anions (Mayer or Wiberg, see the $\mathrm{SI}$ ), including the high electron density $\left(0.31(\mathbf{2 a})\right.$ and $\left.0.36(\mathbf{2 b}) \mathrm{e}^{-3}\right)$ accumulated at the corresponding $\mathrm{Mo}-\mathrm{M}$ bond critical points, a figure remarkably higher than the one computed at the middle point of the Mo-M bond for the corresponding electron-precise anions (ca. $0.22 \mathrm{e}^{-3}$ ). Unfortunately, inspection of the Kohn-Sham orbitals (see the SI) does not allow for a clear identification of the two components expected for a $\mathrm{Mo}=\mathrm{M}$ bond $(\sigma$ and $\pi$ ), this being a consequence of the large orbital mixing taking place. Interestingly, the LUMO of the molecule is mainly centered at the $\mathrm{Re}$ atom while exhibiting partial $\pi^{*}(\mathrm{Mo}-\mathrm{Re})$ character, then suggesting that addition of nucleophiles (under orbital control) should take place at this site. This is nicely confirmed by the easy carbonylation of these anions upon exposure to $\mathrm{CO}$, which yield the electron-precise anions $\left[\mathrm{MMoCp}\left(\mu-\mathrm{PR}_{2}\right)(\mathrm{CO})_{6}\right]^{-}$. In contrast, the most favorable position for the incorporation of electrophiles seems to be indicated by the HOMO-2, which builds up electron density at the intermetallic region, slightly above the MoReP plane (Figure 1), a position found to be the anchoring point for $\mathrm{Au}(\mathrm{I})$ cations, as discussed below.

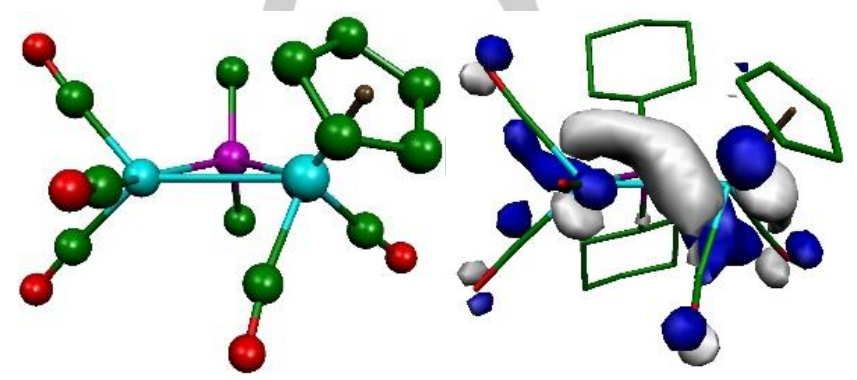

Figure 1. DFT-optimized structure of anion $\mathbf{2 b}$ (left), with $\mathrm{H}$ atoms and $\mathrm{Cy}$ groups (except $\mathrm{C} 1$ atoms) omitted, and view of the HOMO-2 orbital of $\mathbf{2 b}$ (right).

Conceptually, one of the simplest reactions of the unsaturated anions $\mathbf{2}$ might be their protonation to yield the corresponding hydride-bridged derivatives, a process observed for the homometallic anions $\left[\mathrm{M}_{2} \mathrm{Cp}_{2}\left(\mu-\mathrm{PCy}_{2}\right)(\mu-\mathrm{CO})_{2}\right]^{-[6-7]}$ Unexpectedly, however, addition of $\left(\mathrm{NH}_{4}\right) \mathrm{PF}_{6}$ to THF solutions of $\mathbf{2} \mathbf{a}, \mathbf{b}$ led instead to the quantitative formation of the hydridebridged ammonia complexes $\left[\mathrm{MMoCp}(\mu-\mathrm{H})\left(\mu-\mathrm{PR}_{2}\right)(\mathrm{CO})_{5}\left(\mathrm{NH}_{3}\right)\right]$ $(\mathrm{M}=\mathrm{Mn}, \mathrm{R}=\mathrm{Ph}(\mathbf{3} \mathbf{a}) ; \mathrm{M}=\mathrm{Re}, \mathrm{R}=\mathrm{Cy}(\mathbf{3} \mathbf{b}))$ (Scheme 2). This result is consistent with initial formation of the corresponding unsaturated hydride $\left[\mathrm{MMoC} p(\mu-\mathrm{H})\left(\mu-\mathrm{PR}_{2}\right)(\mathrm{CO})_{5}\right]$ (not observed) which, being extremely reactive, would evolve rapidly by addition of ammonia (released upon protonation) to quench the electronic and coordinative unsaturation of its dimetal center, certainly a quite unusual reaction for an organometallic molecule. Unfortunately, using alternative protonation reagents (i.e. $\mathrm{HBF}_{4}$ or $\mathrm{HBAr}_{4}\left(\mathrm{Ar}^{\prime}=3,5-\mathrm{C}_{6} \mathrm{H}_{3}\left(\mathrm{CF}_{3}\right)_{2}\right)$ ) led to complex reaction mixtures from which we could isolate no products. An X-ray analysis of the more stable ammonia complex $\mathbf{3 b}$ (see SI and Figure 2) corroborated the presence of a bridging hydride ligand $\left(\delta_{\mathrm{H}}=-10.56 \mathrm{ppm}, J_{\mathrm{HP}}=20 \mathrm{~Hz}\right)$, and the coordination of the ammonia molecule at the Re fragment $\left(d_{\text {Re-N }}=2.253(3) \AA, \delta_{H}=\right.$ $-0.06 \mathrm{ppm}$ ). As result, a metal-metal single bond should be formulated for these 34-electron complexes according to the $18 \mathrm{e}$ rule ${ }^{[16]}$ a view supported by the Mo-Re length of $3.1876(3) \AA$, which is almost identical to that found for the isoelectronic hexacarbonyl complex $\left[\mathrm{MoReCp}(\mu-\mathrm{H})\left(\mu-\mathrm{PPh}_{2}\right)(\mathrm{CO})_{6}\right]$ (ca. 3.19 Å). ${ }^{[10]}$ 


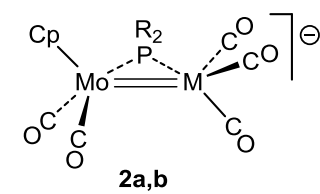

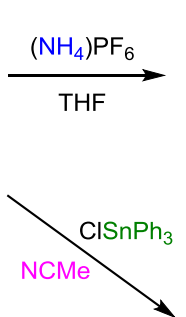

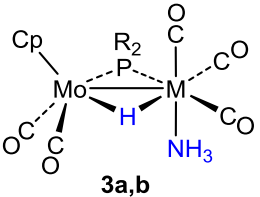

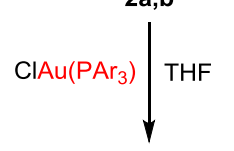

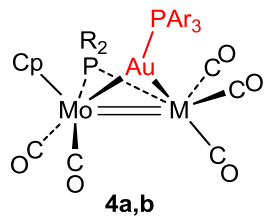
$4 a, b$

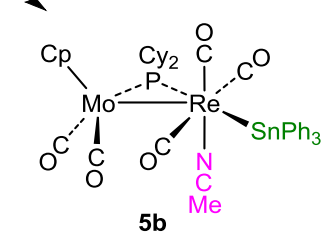

Scheme 2. Reactions of Unsaturated Anions 2

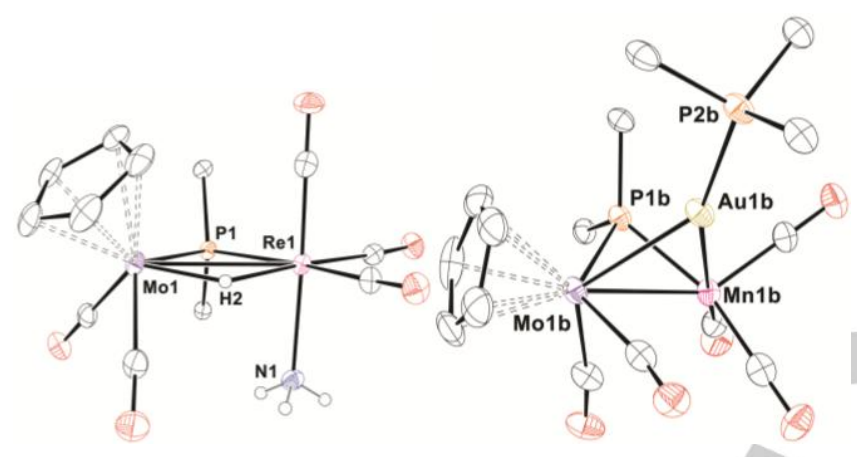

Figure 2. ORTEP diagrams (30\% probability) of compounds $\mathbf{3 b}$ (left) and $\mathbf{4 a}$ (right) with most $\mathrm{H}$ atoms, $\mathrm{Cy}$ and $\mathrm{Ar}$ groups (except their $\mathrm{C} 1$ atoms) omitted for clarity. ${ }^{[17]}$

Other reactions of anions 2 with simple electrophiles such as Mel or $\mathrm{ClCH}_{2} \mathrm{Ph}$ were also explored aiming to prepare unsaturated alkyl derivatives; however, none of these reactions led to isolable organometallic complexes. In order to obtain more stable unsaturated derivatives, we resorted to the reactions with $\left[\mathrm{AuCl}\left\{\mathrm{P}(p \mathrm{Tol})_{3}\right\}\right]$, a source of cationic gold $(\mathrm{I})$ fragments isolobally related to $\mathrm{H}^{+}$, but providing a higher steric protection to the unsaturated centre. Satisfactorily, the reaction of anions $\mathbf{2}$ with the above mentioned gold complex takes place rapidly and selectively to yield the sought unsaturated trimetallic clusters $\left[\right.$ AuMMoCp $\left.\left(\mu-\mathrm{PR}_{2}\right)(\mathrm{CO})_{5}\left\{\mathrm{P}(p \mathrm{Tol})_{3}\right\}\right](\mathrm{M}=\mathrm{Mn}, \mathrm{R}=\mathrm{Ph}(\mathbf{4 a}) ; \mathrm{M}=$ $\mathrm{Re}, \mathrm{R}=\mathrm{Cy}(\mathbf{4 b})$ ) in good yields (Scheme 2 ). An X-ray diffraction study of the $\mathrm{Mn}$ compound $\mathbf{4 a}$ (Figure 2) corroborates the incorporation of the gold $(\mathrm{I})$ fragment at the intermetallic site of the parent anion. The central PMnMoAu ring is significantly puckered $\left(\theta_{\mathrm{PMoMnAu}}=98.8^{\circ}\right),{ }^{[17]}$ which can be rationalised as following from the interaction of the $\mathrm{Au}(\mathrm{I})$ electrophile with the HOMO-2 orbital of the anion. Such interaction does not modify the overall electron count at the MoMn site, therefore a Mo-Mn double bond should be also formulated for $\mathbf{4 a} .^{[16]}$ Indeed, while the Mo-Au (2.7747(6) $\AA$ ) and Mn-Au (2.721(1) $\AA$ ) lengths remain close to those measured for the electron-precise complex [AuMnMo $\left.\left\{\mu-\mathrm{K}^{2}: \mathrm{n}^{3}-\mathrm{C}\left(\mathrm{PC}_{3}\right) \mathrm{S}_{2}\right\}(\mathrm{CO})_{6}\left(\mathrm{PPh}_{3}\right)\right]$ (2.768 and $2.772 \AA$, respectively), ${ }^{[18]}$ the Mo-Mn distance of $2.705(1) \AA$ is dramatically shorter (by ca. $0.3 \AA$ ). In fact, this length falls on the short side of the range of lengths ever measured for bonds between these atoms $(2.68-3.14 \AA),{ }^{[19]}$ although none of the corresponding complexes seem to display $\mathrm{Mo}=\mathrm{Mn}$ bonds. ${ }^{[20]} \mathrm{All}$ the available spectroscopic data for these complexes support the retention in solution of the structure just discussed. In particular, the absence of additional ligands at the $M n / R e$ fragment is clearly indicated by their $\mathrm{C}-\mathrm{O}$ stretches, with a pattern close to those observed for the iodide-bridged pentacarbonyls $\left[\mathrm{MMoCp}(\mu-\mathrm{I})\left(\mu-\mathrm{PR}_{2}\right)(\mathrm{CO})_{5}\right]$.

The utility of anions 2 as precursors of trimetallic complexes was further explored by reacting them with $\mathrm{CISnPh}_{3}$, a reagent leading to the formation of unconventional stannyl-bridged complexes upon reaction with the homometallic anions $\left[\mathrm{M}_{2} \mathrm{Cp}_{2}\left(\mu-\mathrm{PCy}_{2}\right)(\mu-\mathrm{CO})_{2}\right]^{-[6-7]}$ Addition of this reagent to THF solutions of the anions 2 led however to complicated reaction mixtures. This changed dramatically in the case of the Re anion 2b when using MeCN as solvent, then leading to the selective formation of the acetonitrile stannyl complex $[\operatorname{MoReCp}(\mu$ $\left.\left.\mathrm{PCy}_{2}\right)\left(\mathrm{SnPh}_{3}\right)(\mathrm{CO})_{5}(\mathrm{NCMe})\right](5 \mathbf{b})$. The solid state structure of this complex (Figure 3) reveals the terminal disposition of the $\mathrm{SnPh}_{3}$ group at the $R e$ fragment, trans to the phosphanyl ligand $\left(\delta_{P}=\right.$ $217 \mathrm{ppm}$, JPSn $=183 \mathrm{~Hz}$ ), with a conventional Re-Sn single-bond length of $2.7369(5) \AA$ (ca. $2.73 \AA$ in $\left.\left[\operatorname{ReCp}\left(\mathrm{SnPh}_{3}\right)_{2}(\mathrm{CO})_{2}\right]\right){ }^{[21]}$ The coordination sphere of the Re centre is then completed with three CO ligands arranged in a meridional disposition (retained in solution, as judged from the IR spectrum), and by a tightly bound acetonitrile ligand $\left(d_{\mathrm{Re}-\mathrm{N}}=2.152(5) \AA\right)$. The Mo-Re length of $3.1059(5) \AA$ is slightly shorter (by ca. $0.07 \AA$ ) than that found for the ammonia complex $\mathbf{2} \mathbf{b}$, but still consistent with the formulation of a single bond between these atoms.

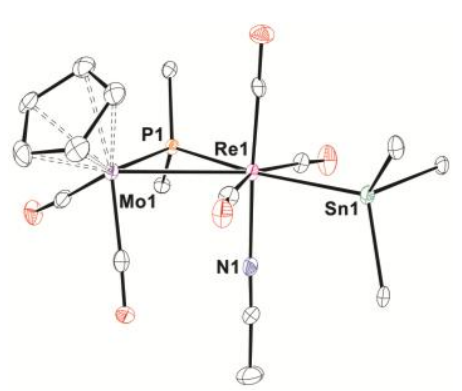

Figure 3. ORTEP diagram ( $30 \%$ probability) of $\mathbf{5 b}$ with $\mathrm{H}$ atoms, $\mathrm{Cy}$ and $\mathrm{Ph}$ groups (except their $\mathrm{C} 1$ atoms) omitted.

\section{Conclusions}

We have developed an efficient synthetic route for the preparation of the unsaturated anions 2 , which are the first anionic heterometallic complexes having Mo-M' $\left(M^{\prime}=M n, R e\right)$ double bonds. These anions display a high metal-based nucleophilicity favoring the incorporation of different electrophiles at the dimetal center, this triggering the coordination of additional donor molecules (i.e. solvent molecules) to render electron-precise complexes. Ongoing work in our laboratory aims to use these complexes as surrogates of 
their neutral unsaturated derivatives (i.e. the hydrides $\left.\left[\mathrm{MMoCp}(\mu-\mathrm{H})\left(\mu-\mathrm{PR}_{2}\right)(\mathrm{CO})_{5}\right]\right)$ in a number of processes.

CCDC 1514512-1514514 contain the supplementary crystallographic data for this paper. These data can be obtained free of charge from The Cambridge Crystallographic Data Centre.

Supporting Information (see footnote on the first page of this article): Synthetic details, NMR and IR spectroscopic data, DFT calculations report (PDF).

\section{Acknowledgements}

We thank the Gobierno del Principado de Asturias for financial support (GRUPIN14-011), the MINECO of Spain for a grant (to E.H.) and financial support (CTQ2015-63726-P), and the CMC of Universidad de Oviedo for access to computing facilities.

Keywords: Heterometallic complexes • Metal-metal interactions - Carbonyl ligands $\bullet P$ ligands $\cdot$ Anions

[1] a) F. A. Cotton, C. A. Murillo, R. A. Walton in Multiple Bonds between Metal Atoms. Springer Science and Business Media, Inc.: New York, 2005; b) N. V. S. Harisomayajula, A. K. Nair, Y.-C. Tsai, Chem Commun. 2014, 50, 3391; c) M. H. Chisholm, Chem. Rec. 2001, 1, 12.

[2] a) L. R. Falvello, B. M. Foxman, C. A. Murillo, Inorg. Chem. 2014, 53 , 9441 ; b) S. T. Liddle in Molecular Metal-Metal Bonds. Wiley-VCH Weinheim, Germany, 2015.

[3] J. P. Collman, R. Boulatov, Angew. Chem. Int. Ed. 2002, 41, 3948.

[4] a) R. J. Eisenhart, L. J. Clouston, C. C. Lu, Acc. Chem. Res. 2015, 48, 2885; b) J. P. Krogman, C. M. Thomas, Chem. Commun. 2014, 50 5115 ; c) B. G. Cooper, J. W. Napoline, C. M. Thomas, Catal. Rev.: Sci. Eng. 2012, 54, 1; d) C. M. Thomas, Comments Inorg. Chem. 2011, 32 , 14.

[5] D. García-Vivó, A. Ramos, M. A. Ruiz, Coord. Chem. Rev. 2013, 257, 2143.

[6] M. E. García, S. Melón, A. Ramos, V. Riera, M. A. Ruiz, D. Belletti, C. Graiff, A. Tiripicchio, Organometallics 2003, 22, 1983.

[7] M. A. Alvarez, M. E. García, D. García-Vivó, M. A. Ruiz, M. F. Vega, Organometallics 2010, 29, 512.
[8] An anionic coordination complex with a triply bonded $\mathrm{MnCr}$ center has been recently reported, see: R. J. Eisenhart, P. A. Rudd, N. Planas, D. W. Boyce, R. K. Carlson, W. B. Tolman, E. Bill, L. Gagliardi, C. C. Lu, Inorg. Chem. 2015, 54, 7579

[9] A. D. Horton, M. J. Mays, P. R. Raithby, J. Chem. Soc., Dalton Trans. 1987, 1557

[10] H. J. Haupt, A. Merla, U. Florke, Z. Anorg. Allg. Chem. 1994, 620, 999.

[11] A. D. Horton, M. J. Mays, T. Adatia, K. Henrick, M. Mcpartlin, J. Chem. Soc., Dalton Trans. 1988, 1683.

[12] H. J. Haupt, G. Disse, U. Florke, Z. Anorg. Allg. Chem. 1994, 620, 1664

[13] P. S. Braterman in Metal Carbonyl Spectra. Academic Press: New York, 1975.

[14] Density Functional Theory (DFT) calculations were performed with the GAUSSIAN03 program package using the hybrid method B3LYP, along with the standard $6-31 \mathrm{G}^{*}$ basis set on all atoms except for $\mathrm{Mn}$, Mo and $\mathrm{Re}$, for which a valence double- $\xi$ quality basis set and LANL2DZ effective core potentials were used. See the SI for further details.

[15] L. Yu, G. N. Srinivas, M. Schwartz, J. Mol. Struct. 2003, 625, 215.

[16] We adopted a "half-electron" counting convention for complexes having $(\mu-H)$ ligands or related groups as $\mathrm{Au}\left(\mathrm{PR}_{3}\right)$, so that $\mathbf{3} \mathbf{a}, \mathbf{b}$ and $\mathbf{4 a}, \mathbf{b}$ are regarded as having $\mathrm{Mo}-\mathrm{M}$ and $\mathrm{Mo}=\mathrm{M}$ bonds, respectively. Other authors recommend the adoption of a "half-arrow" convention for this sort of molecules (M. L. H. Green, G. Parkin, Struct. Bond. 2017, 117, 79 and references therein). Under such convention, however, the above complexes should be assimilated to the corresponding iodidebridged complexes $\left[\mathrm{MMoCp}(\mu-\mathrm{I})\left(\mu-\mathrm{PR}_{2}\right)(\mathrm{CO})_{6}\right]$ (Scheme 1), therefore being formulated with no or single $\mathrm{M}-\mathrm{M}$ bonds, respectively, a relationship which we consider of little use to interpret the strong differences separating the structure and spectroscopic properties of all these molecules.

[17] Values given for one of the two independent molecules of 4a present in the asymmetric unit cell, see the SI.

[18] M. Wang, D. Miguel, E. M. Lopez, J. Perez, V. Riera, C. Bois, Y Jeannin, Dalton Trans. 2003, 961.

[19] F. H. Allen, Acta Crystallogr. Sect. B 2002, 58, 380.

[20] The only structurally charaterized complexes displaying double bonds between group 6 and group 7 metals are a few $R_{2} W$ clusters displaying $R e=W$ lengths of ca. $2.70 \AA$. See for instance: J.-J. Peng, K.M. Horng, P.-S. Cheng, Y. Chi, S.-M. Peng, G.-H. Lee, Organometallics 1994, 13, 2365.

[21] S. W. Lee, K. Yang, J. A. Martin, S. G. Bott, M. G. Richmond, Inorg. Chim. Acta 1995, 232, 57 
Entry for the Table of Contents (Please choose one layout)

Layout 2:

\section{COMMUNICATION}

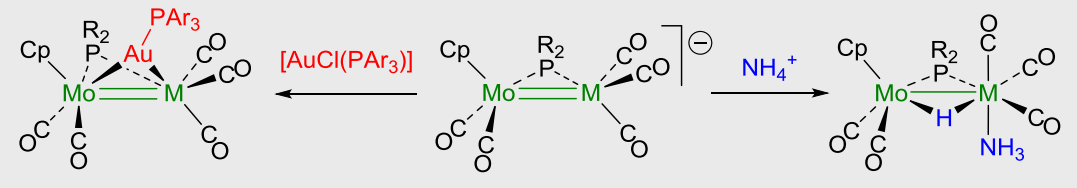

Development of an efficient synthetic route for the title anions permitted the study of their chemical reactivity towards different electrophiles, demonstrating a marked metal-based nucleophilicity which allowed the synthesis of novel heterometallic derivatives featuring electron-precise or unsaturated $M o-M(M=M n, R e)$ centres.
Heterometallic complexes

M. Angeles Alvarez, M. Esther García, Daniel García-Vivó, * Estefanía Huergo, Miguel A. Ruiz

Page No. - Page No.

Synthesis of the Unsaturated Anions $\left[\mathrm{MMoCp}\left(\mu-\mathrm{PR}_{2}\right)(\mathrm{CO})_{5}\right]^{-}(\mathrm{M}=\mathrm{Mn}, \mathrm{R}=$ $\mathrm{Ph} ; \mathrm{M}=\mathrm{Re}, \mathbf{R}=\mathrm{Cy})$ : Versatile Precursors of New Heterometallic Complexes 